African Research Review

An International Multidisciplinary Journal, Ethiopia

Vol. 10(1), Serial No.40, January, 2016:211-224

ISSN 1994-9057 (Print)

ISSN 2070--0083 (Online)

Doi: http://dx.doi.org/10.4314/afrrev.v10i1.16

\title{
Industrial Design: Applied Arts Component as a Factor in Design and Technology
}

\author{
Obasuyi, Osa-Francis Efe \\ Head of Department \\ Department of Fine/Applied Arts \\ University of Benin, Benin City \\ Edo State, Nigeria \\ Mobile No.: 08023112447, 08034484647 \\ E-mail: yandref2013@gmail.com
}

\begin{abstract}
This paper examined the principles of the disciplines of the Applied Arts and Design and their roles and place in Technology and Industry. These principles which is believed to be "intuitive""instructive ", "natural" and help makes up part of what might be referred to as, "that unique sense of rightness ". The paper revealed that the same Design drawing meant for a new concept car in Engineering design also is tenable for design concepts or projects in the Applied Arts and Design. This informed the need and thrust of this paper which was predicated on the consideration of establishing that the role/place of the Applied Arts as a component factor in Design is innately and intrinsically connected to the resultative man-made material culture and society. The paper also established that the principles and practice of problem solving skills and initiatives such as drawing, drafting (draught-manship), modeling or sculpting (in clay or industrial plasticine) styling and prototype creation realized by moulding/shaping of the clay material to assume any contour, shape, form or topology of the given object helps to achieve the ultimate desired product design. This paper recommends that for any design to succeed it must emplace (strictly) the Applied Arts principles as a major
\end{abstract}


component factor in the Design and the Technological process of manufacture of any given design initiative (product/object).

Key Words: Algorithmic/ Heuristic Approaches, Industrial Plasticine, Play dough, Polymer Clay, "Partipris “, Salt dough, Styling.

\section{Introduction}

What has come to us today to be known as the profession/discipline of industrial design began with the "spark" that was triggered off by the monotony of form and aesthetics of mass produced goods during the industrial revolution of the 1860s. At the time, industrially produced goods literally lost the "soul" and "essence" of aesthetics and beauty. Functionality, form and the morphology of manufactured goods became predominantly 'boring' 'hideous' and in some cases, "outright ugliness" took over. (Morris 2009) For instance, the Deutscher werkbund, in Germany founded in 1907, was a precursor to the Bauhaus school which was the German state effort and attempt in education to integrate traditional craft practices with industrial mass production techniques.

The very foundation of craft and craftsmanship which was the bedrock and springboard from which innovation, invention and the start of the Age of discoveries got its roots, gradually gave way to a revolution of goods and products being "churned out" of the Assembly line, like "lifeless" and cold "effigys" of what the machine age, became known for. The original role and place of craft and craftsmanship, artistic traditions and the role of custom- made hand-crafted goods which are the hallmark of masterpieces of the craft and time honored tradition of the Middle Ages, were quickly swallowed up by the Assembly line production of mass produced goods for the mass market of an era of consumerism and mass production (Archer, B 1970).

So saw the birth of a profession between 1800 - 1866 (to be precise) where a group of arts and craft practitioners came together to form what became known as the Arts and Craft movement Spearheaded by the British artist/architect - William Morris. His works and activity in graphic Design, textile design and architecture were so prolific that his printing press the (kelmscott Press) became synonymous with the arts and craft movement. These and the achievement of others like him became the spring board for the takeoff of the new profession called industrial design.

\section{Applied Arts as a Factor in Design and Technology}

These contemporary achievements and the influences of Applied Arts as a factor could be largely attributed to the industrial design aspects/components of Branding, Styling, Bionics and Ergonomics to mention a few. Industrial design utilizes the Applied Arts, applied sciences and pure sciences in the development and improvement of the given product as it accentuates the qualities of beauty, aesthetics, 
design, ergonomics (Man-machine Relationship or handling), functionality and/or its usability and its ultimate marketability.

A few of the related fields/discipline which reflects these component factors of the applied arts and industrial design are: Graphic Design, Products Design, Interface design, Transportation/Automobile design, Visuals Design, Web Design, Urban Design, Architecture, Communication/Information Design, Computer Science and Technology etc. Archer, B (1974) amplifies the opinion of the school of thought that says that: Design in its broader perspective could be defined singularly and severally as the creation of a system, or goods/services, a blue print, an engineering drawing or an object intended to accomplish set targets that satisfies defined goals/objectives, which in turn is intended to meet with specific needs or fill up the avoid in any given/particulate environment. It (design) could also be described as the application of a given set of parameters which tends to satisfy a given set of standards and requirements in the hope and attempt at creating or bringing to being, a new or Novel creation or being in the form of a new design entity. Barnwell, M (2011). Design as a process of pre-specified and preplanned actions, presents such a process of design as an activity which involves a series of preplanned actions, taken during and after the process of designing to bring to fruition an intended design initiative.

According to Newell, A. and Simon, H. (1972). The process of Design sometimes adopts the Algorithmic step by step approach to problem solving. An approach which helps defines the very nature, form specifications, costs and even the actual production process. Taking into cognizance the legal, social, political and economic constraints of the design and production climate. Obasuyi, F. (2010) in his work also alludes to the fact that the word design or industrial design is widely associated with applied arts. The boundaries between art and design are blurred. Some terms such as "intuitions" and "ingenuity" in design is shared also across the disciplines of applied arts and design. Other terms that are also as instructive are intuitive designs which could be read to mean "very instructive", "built in" "natural" and makes up part of what might be referred to as "that unique sense of rightness". When viewed from the perspective of what affects or influences the consumer of products of design for example, the design drawing employed in the production of a concept car in engineering for instance, is also applicable in the actualization of the applied arts processes and also in design of end products. Most often than not with emphasis placed on function and utility in engineering design

\section{The Prototype: What Is It?}

Morris, R. (2009) puts it succinctly thus: that a prototype means first impression which is taken from two Greek words 'protos' and 'typos' or prototypon' meaning 'primitive form' which also means the early sample, model, mock-up of the intended product built consciously to test a concept or process or act as the real thing 
to be created or replicated. The prototype is built to test and try a new design to enhance precision and perfection. It provides specification for a real working system/model of what the real product would ultimately look and function like.

The role and place of sketching draughting (drafting) modeling (especially use of clay/plastiscine in modeling) styling and prototype production in design and production engineering are so intrinsically embedded in the very foundation of production and life span of any cycle of bringing into existence the given industrial goods/product.

The applied arts component of sculpting/sculpture using industrial plasticine, a material that is malleable and can easily be shaped to assume any contour, shape, form or topology of the intended product undergoing design, will eventually result in the model or prototype which visualizes the given product before it's eventually manufactured. The prototype in this case as mentioned above is the early sample, model or mock-up of the intended/envisaged product. It is built consciously to test a new concept or process or it could also act as the real thing to be created or replicated. The prototype also as mentioned earlier is built sometimes to test or try a new design or to enhance the precision and perfection of such a product. It is sometimes the ultimate look-a-like both in function size, aesthetics and specificity of form and actuality of purpose desired

Arther, B. (1974) Ibid and Barnwell, M (2011) Ibid; jointly and severally acceded to the fact that the term design is more often than not associated with applied arts as could be evidenced by the teachings and works of Ramond Loewy, at the Bauhaus and Ulm school of Design in Germany. They also proffered that Design viza-viz Applied Arts is or have become component parts of the engineering process. However deducing from all of the above, is the obvious and more accepted view (or belief) that engineering is considered a "science", (just like in the late 1800s when machine manufactured goods were considered scientific inventions wayback then. Nevertheless, there comes along the question and the argument even today of what is considered science in the first place? This situation could be compared with the following two analogies of distinction; as posited by some scientists at the Rank Xerox corporation lab in America; who made the distinction of design versus science/engineering thus; the one could be described as "craft and ingenuity" put against beauty and the aesthetic sentiments that appeals to human nature and soul, (which represents design) versus "moving atoms" i.e. the pure physical sciences of engineering. Which focuses fundamentally on functionality and/or utility of the manufactured product on the other. So the norm is that, engineering is applied to design with emphasis on function and the utilization, or application of maths and the sciences. This hypothetically, has been the premise and is the foundation for which the manmade environment is structured and built. But the reverse order is the case 


\section{Industrial Design as a Profession}

Archer, B. (1974) ibid; emphasis that the meaning of industrial design as a profession dwells on the exploration and study, form and function of the intended design initiative with a focus on the meaning and connection between the product, the consumer and the environment in which the product is to function or intended to be used. He continued by saying that industrial design is that professional service aimed at creating and developing ideas and concepts tailored to specification of products that optimizes the function, value (quality, aesthetics and beauty) i.e. the appearance and look of the product that accedes to the mutual benefit and satisfaction of both the consumer and society on the one hand, and the manufacturer and economic benefit/development of society on the other. Obasuyi (2010) also proffered that, looking at design from another perspective, it could be described as the result of the acquisition of a critical set of objectives or framework used for the analysis and creation of manufactured products (artifacts, craft work or custom made goods etc).

There could be a more precise way to look at design from the point of view of pragmatism and realism which according to Coelho, A. (2011) who stated that "Design could be considered to be that process of taking something (an object, devise or a system) from its "existing state" (the intended object of Design needing a new birth, renewal, recreation or reintroduction) and moving it to a "preferred state". This description of design perfectly fits the conception and belief to which I subscribe to in more ways than one. For example, this definition applies to the invention or creation of a totally whole new range of goods, services and systems that were hitherto nonexistent. It could also be ascribed to a situation where design is applied to an existing state of being of a product that needs reintroduction, or needs to be Rebranded or improved upon and given a totally new outlook or given a "breath of fresh air" from the original state of the product needing a redefinition of its look form and make-up, Morphology, shape and size as it is transformed to the preferred state of the final finished look of finesse, perfect beauty and aesthetic elegance.

Furthermore, industrial design or design could also be compared to the use or both applied arts and applied science (and their unique/industrial principles) to improve the aesthetics (beauty), form, ergonomics, (the man - machine interrelationships) which enhances and improves upon the functionality and or usability of the given product or service. The role of design as a discipline/profession is to help create and bring to life acceptable design objects/solutions aimed at resolving the problems of form, functionality, usability, marketability, brand development/evolution and the overall sales potentials of the given product. Design focuses principally on the "aesthetics" and the "user-interface" aspects of the manufactured product. 
AFRREV, 10 (1), S/NO 40, JANUARY, 2016

\section{Design and Modeling}

In the process of the design, development and production of new products, craft- workers, designers and engineers rely on the ingenuity, and conceptual intuitiveness of the Applied artists, sculptors, architects, graphic designers and visual display Professionals (and of course production/mechanical engineers) to bring to being (or to life) the new product so desired.

In the study of design processes/applications and procedures especially that of modeling and product manufacture/production, there is what is called the design strategies called "top-down" and "bottom-top" design approaches. These approaches according to Drexler, K. (1992) are described as: follows:

1. The Top-Down Approach: Design strategy: This is the strategy invoked or used in information processing and knowledge, and in the field of Nanotechnology- which is the manipulation of matter of at least one dimension size from 1-100 nanometers on an atomic, molecular and super molecular scale to achieve a consistent whole or macroscale products, which is also referred to as molecular nanotechnology; it is also used in a variety of fields including "systematic", humanistic/scientific theories. It could also be seen as a style used in creative thinking - a branch in the study of creative strategies and creativity. It is also called the "stepwise design" approach or a synonym of "decomposition" This means essentially, the breaking down of a given system or product to gain insight into its compositional, sub-systems or working/functional parts (internal/external). Each of the systems are looked at or examined in greater details, until the entire specification is reduced to its base elements/parts. A model or a mock-up is produced to make for the easier understanding and manipulation of the system/ product that is to emanate from this approach type. Put succinctly the "top-down" approach begins with the complete picture and this is broken down into smaller segments or component parts.

2. The Bottom-Up Approach: Design Strategy: The second approach is the "bottom-top" approach which is essentially the piecing together of parts or component parts of a system to give rise to a more complex system or product. It begins with information/data or a set of concepts or ideas (ideation) which comes into the design effort/process from one direction or point (which is known as the "input") and is converted into an image or concept by the designer who interprets these concepts as perceptions or "outputs". This strategy involves the individual elements or component parts of the design which are specified in great details. Then these various elements are linked together to form a larger more complex sub product or sub system which in 
turn is linked to many other levels until a complete super-structure or system/product is produced.

In product design and the developmental life cycle of new products, designers and engineers employs both the top-down and the bottom-up approaches in the various processes of design. For example, the bottom-up approach is used when an existing off the self or existing component is integrated into the new or given product intended for production. The top-down approach ensures that the receiving parent product or component needing a newly designed part would have to be redesigned around the selected component intended to be put into it to fit properly.

\section{Clay Modeling (Design and Styling)}

Clay and its uses in the design process/endeavour is representative of any soft and malleable substance or material often used in the actualization or in the realization of the form or morphological structure, makeup or buildup of the intended product. For industrial design purposes, there are four types of clay varieties or malleable substances that could be used in designing, building and sculpting of products or systems. In each of these, the material composition and their application in the production processes vary considerably. For example, the intended model or intended product is first created in Natural Kaolin clay, or in other times could be made up of a wooden or iron frame called "Armature" or also sometimes made from the material called Styrofoam. As in the case of clay, this material is smoothed over the frame or "Armature" using sculpting tools to shape and size the product intended into existence.

\section{Modeling: Methods and Materials}

\section{a. Industrial Plasticine}

This is an industrial modeling material, mainly used in the automotive design industry. Industrial plasticine's composition is wax-based and made up of calcium salts and principally calcium carbonate, petroleum Jelly, a long chain of aliphatic acid (stearic acid). It is non-toxic, sterile, soft, and malleable and does not dry up on exposure to air. It is made of wax which has a chemical make-up that contains sulphur, a yellowish substance with an unpleasant smell found in rock formations usually mined from the earth. It is the sulphur that gives plasticine, the characteristics smell it's known to have. It is a soft, elastic and malleable substance usually associated with children's toys and very popular with animation/animators of children films/movies and also in the motor building industry. It is ideal for moulding and preparing cast moulds for P.O.P. (Plaster of Paris). It is mouldable enough to create a product and flexible enough to allow for the creation of moving parts to interlock and be integrated into whole parts of products when and where the need arises. Originally plasticine was grey in colour when it was first invented, but it is however now found in a variety of bright colours. 
It is widely used and popular with kids and in schools for teaching art. Plasticine is known by various trade names e.g. plastiline, claymate or newplast etc.

It is therefore pertinent at this point to look at, discuss and throw more light on four of these types of other clay materials and they are as follows:

a. Oil-based Clay: This type of clay is made from various combination of oils, waxes and various clay materials/ components, as the oils are not prone to evaporation or is not water permeable, so they remain malleable even in very dry surroundings and could be left for long periods without shrinking or reduction in weight or size. Although, increase in temperature could influence the characteristics and quality of rendition in its application during modeling. Because oil-based clay is not soluble in water, it can be re-used over and over again, which makes it also a very popular material for animation. Amongst its other characteristics, they come in a variety of colours and they are non-toxic.

b. Polymer Clay: This is a modeling material that does not shrink or change its shape during the process of extreme heating. Even if it's called clay, it does not necessarily contain any clay materials. Polymer clays are those modeling materials that exhibit qualities of static form shape to shape, frame by frame and section by section. Polymer clay is that clay that is made up of a synthetic compound consisting of large molecules of clay compounds that are linked in a series of repeated simple monomers, which combines several monomers to form a polymer or a polymeric compound. In organic chemistry, it's known as a long or large molecule consisting of a chain or network of many repeating units of molecules formed by chemically bounding together many identical or similar small molecules called monomers. This process of bonding is called polymerization which is the joining together of many monomer molecules. Related examples of compounds consisting of polymers include polyurethane, foams, PVC, (poly vinylchlorides) and Styrofoam (which is used in packaging of electronics/electrical products). The ones mostly used in the design industry are the compressed hard packed version of Styrofoam, which could be shaped, cut, sculpted or chiseled into the required or desired shape or morphological structure of the product desired.

c. Paper Clay: this is a clay type to which fibre (which is cellulose fibre) has been added to increase the tensile strength of the dry clay to dry fast. It is mostly used by potters or sculptors to mend cracks in their works in dry conventional clay. Paper clay is very close and similar to conventional earthenware clays. It could be used primarily for making of dolls for kids or could also be applied in professional ceramic art studio pottery or in sculptured 
art forms. They're cellulose based substances that are lightweight and dries or turns to a firm composition on coming in contract with dry air.

\section{Other Types of Modeling Materials.}

Other types of modeling materials are:

i. Salt dough: Which is a modeling material made from a mixture of flour, salt and water with food colouring to give it distinctive colours. Salt dough is good in making solid sculptures or decorative pieces for figurines and gift items.

ii. Play dough: This is a modeling material commonly used by children for art and craft projects in school. It is made up also of flour, salt, boric acid, water and some mineral oil which acts as binders. It also contains a starch based binder, lubricant, a preservative, hardener and colours with a petroleum additive to give it a smooth feel. It is a non-toxic, non-staining, reusable material that is pliable, and putty-like in its consistency. Another name for this material was originally called wallpaper cleaning putty. It was used informally for cleaning off soot stains from wallpaper. It is very good for producing Marquette's and mascots for new products.

\section{Design Conceptualization and Development}

A design concept (or to conceptualise) could be termed to mean, an understanding, belief or a system that is borne out of, or in the mind, either from or by experience, reasoning and/or imagination of the given individual. It could also be a generic or basic form of abstraction or mental impression of a particular set of ideas or ideology of instances or occurrences in real life or a contrived/imaginative world. Obasuyi (2010). It could also be called a notion or an abstract or general idea inferred or derived from specific or simulated case scenarios.

Deducing or stretching that further, therefore, conceptualization according to Morris (2009) Ibid; could mean the invention or contrivance of an idea and sometimes the formulation of this idea mentally and sometimes ensuring it becomes a reality physically or can be actualized through physical products goods and services. It could also mean the process of formulation, of a proposed form, thing or a phenomenon; it is that act of conceptualizing an idea or thing and bringing it to reality.

The conceptual development of a design and its product derivatives follows certain specific procedural, sometimes Algorithmic or other times heuristic processes of the problem solving endeavour that makes design what it's all about. One of the most fundamental of these processes/principles in the Activity called Design is Sketching; 


\section{Sketching}

This is the rudimental/fundamental stage in the design process and design endeavour. It could also be called drawing, drafting, draughting (draught-manship) or visualization/visuals. Some of these terms are used interchangeably at the prescribed stages of the design life span of a product or service. Sketching could be referred to as an art or applied graphic design work that is executed with design tools such as graphite, pencils, pen and ink, coloured markers, pastel, gouache poster colours or directly on design compliant/enabled computers e.g. use of computer software such as designs done using Element 3D video co-pilot, Auto desk Maya, Alias software, Adobe After Effect, MAXON Cinema 4D, e.t.c. Most of the contemporary design sketching and technological applications has long overtaken the old and traditional/conventional drawing/sketching techniques applied in the process of bringing to life a new product. At other times, the Design process might even just eliminate altogether the 2D paper sketching stage and present the 3D model of the intended product in 3Dimension using materials such as clay, Plasticine, Styrofoam or Wax or better still in 3D printing technique, that is making the rounds and creating Rave reviews right now in design technology and manufacturing industry (that may just be the subject for another paper in future).

A sketch more often than not implies or refers to loosely drawn art work or 2D drawing were the sketch is used to a greater or lesser degree as a means for registering the intended work-able solution of the idea or concept derived from the original concept base.

\section{Design Concept-Developmental Cycle}

The very essence of the design process begins with the acquisition of a viable or credible conceptual idea that has or is a result of a lot of research (resources, analysis) effort aimed at generating or providing the desired design solution to a given design initiative. What could be called in the profession as "Bridging the divide" "filling a void", or simply generating new varieties or new models/editions or brands of the given product or service or maybe a simple repetition (copy) or a known pre-existing design/model requiring minimal change.

On the conclusion of the selection process by the production team of the intended design object, the production team which is often made up of a collective of craftsmen/handymen, Architects, industrial designer's sculptors, engineers and other creative professionals, all come together to determine what is the cost of materials and of all of the other design inputs that would be needed to bring about the actualization of the design initiative. As stated earlier above, the design proper begins with the applied artist or industrial designers, putting unto visual 2D representational display, or images of the various or individual conceptual ideas so desired. This conceptual 
image is presented most often than not in full colour 3D visual representation of the look-alike or of what the real product would look like.

Sometimes working drawings with cross-sectional drawing/or diagrams (with annotational notes) all drawn to scale with all the dimensions and specifications of the size and form of the given product drawn to scale and specification. Sometimes an accompanying mock-up of a 3D model or prototype goes with the $2 \mathrm{D}$ visual representation. Before any product model is launched, computer models are made sometimes in the ratio 1:4 or 1:1 are built to get an impression of the final product. They could be created or crafted in clay, plasticine or Styrofoam.

In all of these design efforts, the role of computer Technology and computer aided design and all of its applications cannot be overemphasized. The computer applications and software packages discussed earlier like the Element 3D video copilot Autodesk Maya, Adobe After effect, Alias design packages, and MAXON Cinema, 4D to mention a few are some of those design tools employed in the actualisation of the design initiative so intended. So the term- "STYLING" or design styling or computer-aided styling comes to the fore as the next stage in the conceptual developmental cycle of a product.

\section{Styling}

All the design concepts. and 2-D visuals so realized are translated or transformed into 3D digital imaging/surface modeling to ensure that the 3D models so developed meets with the Aesthetic requirements and specifications of the designers expectation as well as meets with all the engineering and manufacturing requirements. Styling as a technique in the design process also ensures that both the technical as well as the Aesthetics components harmonises for the optimal utility, form and function of the intended design product. Tools mostly used in styling by product engineering/styling team are Autodesk, Alias and ICEM SURF software tools. The styling production team often consists of the chief industrial designers, interior designers and the engineering experts. In some case all three roles are role into one designer. Other members of the production team are the colour and trim designer, the clay model team, the styling team, studio heads/managers, and prototype engineers/designers. An average number of members of a design team for example could reach up to 20 and the time frame for a concept developmental completion could range between 24 to 36 months in certain instances.

\section{Design Concept: Execution, Production and Completion}

\section{Design and Production}

In the execution or completion of a design initiative certain elements and universal steps or stages needs to be fulfilled. 
These stages are:

(i) Figuring out what is required or needs to be done

(ii) Brainstorming for possible ideas and design options

(iii) Creating the visual design in 2D and 3D models, mock-ups or prototypes

(iv) Generating, creating and executing the product proper.

Digesting that further, the approaches adopted before, during and after the design, process begins, are enumerated in the simple algorithmic/sequential step by step approach. This is consistent with the rational model and method of Design Development/Execution.

\section{Examples of these Algorithmic Sequential Step by Step Process includes:}

(A) Pre-production stage of Design

- Design brief which could be called "partipris" This is the early or (beginning) statement of the Design goals, targets and objectives and all of what the Design project is made of or contains or intends to achieve or look like. Its target goals/objective.

- Analysis: This involves the analysis of the prevailing circumstance or status of the product in question. The prevalent issues (pro and cons)

- Investigative Research - search for similar design solutions or for related design analogies and also for alternative initiatives.

- Specification or Narrowing down to probable or possible options while specifying design requirements and product design specification as to form, shape, colour, dimension, weight, existing final state whether liquid solid, paste, viscous or Amorphous and so on.

- Problem-solving: This is the actual execution stage of conceptualization and documentation in 2D and 3D of the Design solution or initiative. Here is where all the Artistic, modeling, styling (computer styling, Rendition and production) prototype production and final fabrication of the real product all come to a climax.

- Design during production: Design development, improvement, amendment and enhancement of the chosen design solution/initiative to ensure it meets with the desired Design objectives.

- Testing, functionality and usability: of the product so achieved or designed.

- (B) Post Production Stage of the Design 
- Post manufacture feedback from which future designs and successive models might emanate.

- Implementation: Introduction of the product into the preferred environment for which it is to be used or function.

- Evaluation and conclusion: A summary of all the Design processes and the results achieved there from to act as a guide for future improvements.

- Redesign: Any or all of the design process might be repeated with corrections for earlier errors made.

\section{Conclusion}

The evolution of such innovative discoveries in science and technology in the last two centuries has seen to the rise of and adoptions of new ways of doing things. With the (introduction of the computer, the CAD/CAM and CAF (Computer Aided Design manufacture and fabrication) CGI, (computer generated images) and most recently and most importantly the adoption and application of the 3D printing technology, has raised the dyke a bit higher for the fields of Industrial Design and Engineering. The 3D printing technology is a technique that ensures that $3 \mathrm{D}$ objects could be reproduced by a Consumer friendly $3 \mathrm{D}$ printer. These printers can produce a plastic like model or look- a-like of the object intended for reproduction as opposed to the traditional printers that only spreads ink across a $2 \mathrm{D}$ surface, while attempting to create an illusion of Depth of the third Dimension.

The nuclei or hub of the performance activity that binds Design to the ephemeral material world of man are to be found or embedded in the three main attributes and fields of Design and they are that:-

(i) Design acts on the physical world

(ii) Design addresses human needs

(iii) Design generates the built man-made environment

From all of the foregoing therefore, it is ever more than now, pertinent to submit that the discipline/profession called design embraces and epitomizes the component factor of the Applied Arts, while in the same vain the applied arts represents the nucleus around which, all the other elements of Design, Engineering and Technology revolve. 


\section{References}

Archer, B. (1974). Design awareness. Toronto: Thorn Press. London.

Barnwell, M. (2011). Design, creativity and culture. New York: Black Dog Pub.

Bowman, D. \& Hodge, G. (2006). Nanotechnology: mapping the wild regulatory frontier. Futures $38(9)$.

Dyson, .J. (1997). Against the odds, London: Orion Pub.

Derxler, K. (1992). Nanosystems, molecular Machinery, manufacturing and computation. New York: John Wiley and Son.

Coelho, A. (ed.) (2011) Industrial Design-New Frontiers Retrieved Dec 12, 2015 from http//www.intechopen.com/books/industrialDesign-New Frontiers. In Tech open Access Pub.

Hawker, C. (2005). The inventors mind. Columbus USA: Triden Design Press.

Hekkert, P. \& Schifferstein (2008). Product Experience. Amsterdam: Elsevier science Ltd Pub.

Koberg, J. (1991). A soft system guide to creativity and problem solving. New York: Kaufmam Pub Ltd.

Meikle, J. (1979). Twentieth Century-Industrial Design Engineering in America, (1925-1939).Temple University Press, U.S.A.

Morris, R. (2009). The fundamentals of product design. London: AVA Pub.

Newell, A. \& Simon, H. (1972). Human problem solving. New York: Prentice Hall Inc.

Norman, F. (2002). The design of everyday things. New York: Basic Books Pub.

Obasuyi, O. F. E. (2010). Industrial Design, the Nexus between Arts and Technology, Nigeria art Reflections. Journal Society of Nigerian Artist Vol. 9. Ibadan, Nigeria.

Pulos, A. J. (1988). The American design adventure. Cambridge: Cambridge Mass MIT Press.

Roozenburg, J. M., Eekels, J. (1995). Product design fundamentals and methods of design. New York: John Wiley and Sons. 